\title{
Evaluation of the Dallas Thompson Riverscreen Site on the Touchet River
}

\author{
Prepared by \\ Mickie Chamness \\ Pacific Northwest National Laboratory \\ Richland, Washington 99352
}

\author{
Prepared for \\ U.S. Department of Energy \\ Bonneville Power Administration \\ Division of Fish and Wildlife \\ P.O. Box 3621 \\ Portland, Oregon 97208-3621
}

Project No. 1996-011-00

Contract No. 00000652-0034

July 2007 


\section{Summary}

Riverscreen irrigation pumps are a relatively new design in which the pump intake floats on the river surface, pulling water in only from the bottom side and surrounded by a selfcleaning screen. The Walla Walla County Conservation District recently started replacing old pump screens with the Riverscreen and was interested in whether the screens are protective of juvenile salmonids. Pacific Northwest National Laboratory evaluated approach velocities and operations at the Riverscreen installation on the Dallas Thompson property, approximately $3 \mathrm{mi}$. north of Touchet, Washington and $300 \mathrm{ft}$ north of Hofer Dam, on June 18, 2007. Evaluation of this site consisted of underwater videography and water velocity measurements.

The Dallas Thompson Riverscreen was pumping approximately $930 \mathrm{gpm}$ during our evaluation, which is close to the maximum pumping rate for this model. Underwater videography showed only slow movement of water-borne particulates toward the pump

intake, and the screen material was clean. All water velocity measurements were taken below the pump intake opening and between 3 to 6 in. from the screen face. All approach velocities (flow toward the screen and pump) were below National Marine Fisheries Service draft guidelines for juvenile fish screens. 


\section{Acknowledgments}

We are thankful for the support of Gary James and Preston Bronson, Confederated Tribes of the Umatilla Indian Reservation, and Sarah Branum, Bonneville Power Administration, in securing funding for this work. We also appreciate the assistance received from Greg Kinsinger, who arranged for and helped perform the evaluation. Cherylynn Tunnicliffe, Pacific Northwest National Laboratory, helped perform the work. 


\section{Contents}

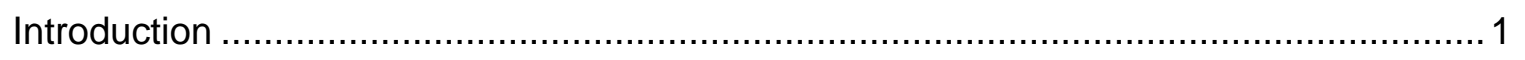

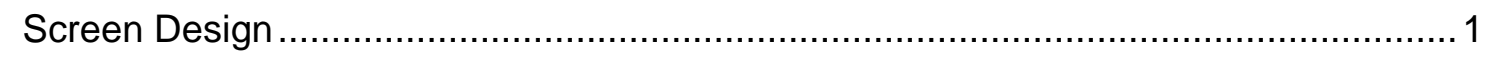

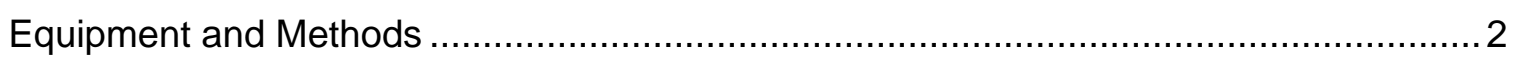

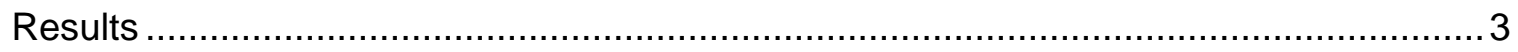

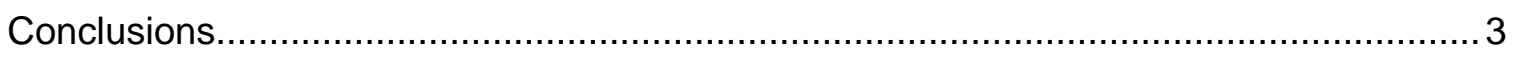

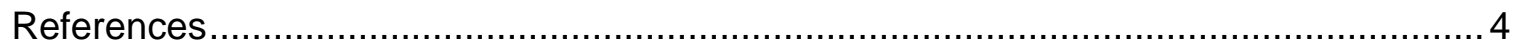

\section{Figures}

Figure 1. Riverscreen Operating at the Dallas Thompson Site......................................... 2

Figure 2. Dallas Thompson Riverscreen Water Velocities, June 2007 ............................. 4 


\section{Introduction}

The Walla Walla County Conservation District has recently been installing Riverscreen irrigation pump systems on the Walla Walla and Touchet rivers. The largest of these screen systems is described as capable of pumping up to 1000 gallons per minute (gpm) without causing approach velocities (toward the screen face) to exceed the National Marine Fisheries Service (NMFS) draft criterion of 0.4 feet per second (ft/s) (NMFS 1995). However, no measurements were available to confirm this claim.

Mr. Greg Kinsinger, Walla Walla County Conservation District, made a request in fall 2006 to the Bonneville Power Administration to have Pacific Northwest National Laboratory (PNNL) evaluate at least one of the existing Riverscreen sites to determine if this screen design maintains approach velocities below the NMFS criterion. Mr. Kinsinger selected sites on the Touchet and Walla Walla rivers for evaluation in December 2006, but rains had increased the debris load and water levels, making the work unsafe.

On June 18, 2007, PNNL researchers were able to perform underwater videography and measure water velocities at the Dallas Thompson site (just upstream of Hofer Dam on the Touchet River) to evaluate whether the 10-in. Riverscreen at this site meets the NMFS draft criterion to protect juvenile salmonids.

\section{Screen Design}

Smaller irrigation pumps are typically set on the bottom of streams with some kind of wire screen or mesh around them to prevent debris from moving into the irrigation system. These screens were not self-cleaning and could plug up, creating extra work for the pumps and the farmer, as well as potentially high water velocities in those areas of screen not plugged. In addition, farmers often disturbed the streambed to create pools of water for their pump intakes.

The Riverscreen (Riverscreen Inc., Clay Center, Kansas) was designed to be a selfcleaning pump intake with low approach velocities that floats on the stream surface, eliminating the need to disturb the streambed to maintain submergence. The model we evaluated had a 10 in. diameter suction pipe surrounded by a small rotating drum screen that is $32 \mathrm{in}$. in diameter and $48 \mathrm{in.} \mathrm{long.} \mathrm{The} \mathrm{drum} \mathrm{screen} \mathrm{is} \mathrm{covered} \mathrm{with} \mathrm{wire} \mathrm{mesh}$ with openings 0.075 in. on a side, providing an open area of $56.3 \%$, meeting the NMFS criterion for screen materials to protect salmonid fry.

This irrigation pump intake floats between two pontoons, with approximately 7 in. of the drum screen submerged (Figure 1). Water is pulled through a $40 \mathrm{in}$. long slot cut into the bottom of the suction pipe. The slot tapers from $3.75 \mathrm{in}$. at the far end to $2.5 \mathrm{in}$. at the pump end. Metal strips mounted lengthwise and perpendicular to the drum surface act as fins to help the drum rotate. A pump on land pulls water into the intake. Some of this water is then used to drive small jets of water on the upstream side that push on the metal fins to turn the drum. Other jets inside the drum spray outward on the downstream 
side to push debris off the drum face. Depending on the diameter of the Riverscreen and size of the pump, these devices can pump from 200 to $1000 \mathrm{gpm}$ (0.45 to $2.2 \mathrm{cfs}$ ). The manufacturer had no data on measured approach velocities for any of these screened pump systems.

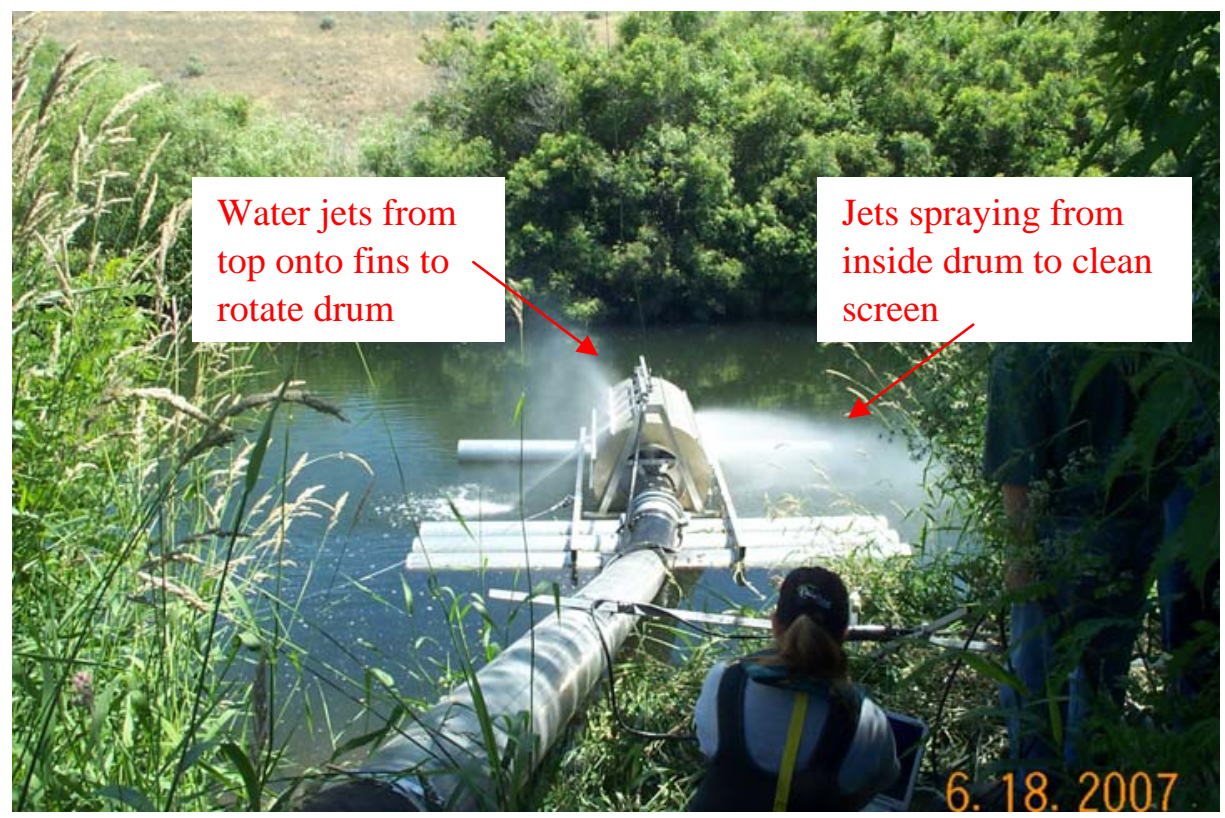

Figure 1. Riverscreen Operating at the Dallas Thompson Site

\section{Equipment and Methods}

The following is a brief discussion of the equipment and techniques used. A more detailed description of the equipment and techniques is provided in Chamness et al. (2007). Underwater videography was accomplished using a digital deep-sea camera (DeepSea Power and Light, Inc., Model MULTI-SEACAM 1050) mounted on a long pole and connected to a digital video recorder (Sony Video Walkman, Model GV-D800), which in turn was connected to a pair of video glasses (Olympus Eye-Trek, Model FMD200). This setup allowed the operator to see real-time what the camera encountered and focus in on areas of interest.

Water velocities in front of the screen were measured using a SonTek acoustic Doppler velocimeter (ADV, SonTek/YSI, Inc., San Diego, California). The ADV probe emits sound at $10 \mathrm{kHz}$ and measures the difference in the frequency of returning sound waves to determine the water velocity. These data were stored directly onto a computer. Normally the probe is oriented to measure sweep past a screen face and approach perpendicular to the screen face. In this case, the probe was positioned beneath the drum screen to measure the approach velocities moving up toward the pump intake.

The Riverscreen system we evaluated was 10 in. in diameter, capable of pumping up to $1000 \mathrm{gpm}$. During our evaluation, the pump was running almost at maximum, 
withdrawing water from the Touchet River at a rate of $935 \mathrm{gpm}$. The water jets were turned off during velocity measurements and videography to minimize water disturbance.

\section{Results}

Underwater videography showed slight water movement toward the pump intake as evidenced by particulates in the water column slowly moving toward the drum screen. The pump intake's area of influence appeared to be less than $1 \mathrm{ft}$ from the drum screen. The screens appeared to be free of debris.

Velocity measurements were made at three positions along the drum screen, identified as being near, middle or farther from the pump (Figure 2). The probe was positioned directly below the intake slot and was between 2 and 6 in. of the drum screen. Approach velocities ranged from 0.01 to $0.09 \mathrm{ft} / \mathrm{s}$, well below the NMFS criterion of $0.4 \mathrm{ft} / \mathrm{s}$. The highest approach velocity was measured at the near end, which is closest to the pump, while the lowest was measured at the far end, farther from the pump.

River velocities are represented by the sweep measurements. These are highest near the middle of the drum. The pontoons holding the system at the river surface probably reduce river velocities at either end of the drum screen, while the middle position is more representative of river velocities moving past the drum screen.

\section{Conclusions}

The Riverscreen evaluated along the Touchet River is the largest model that is capable of pumping up to $1000 \mathrm{gpm}$. The jets appeared able to keep small debris off the screen by rotating the screen and pushing debris off the downstream side of the drum. The Riverscreen system met NMFS draft criteria for screen material and approach velocities, and should not cause impingement of juvenile salmonids. However, because this system floats, it is able to function when stream discharge is low, creating the potential for decreased habitat for fish by significantly lowering stream levels. 


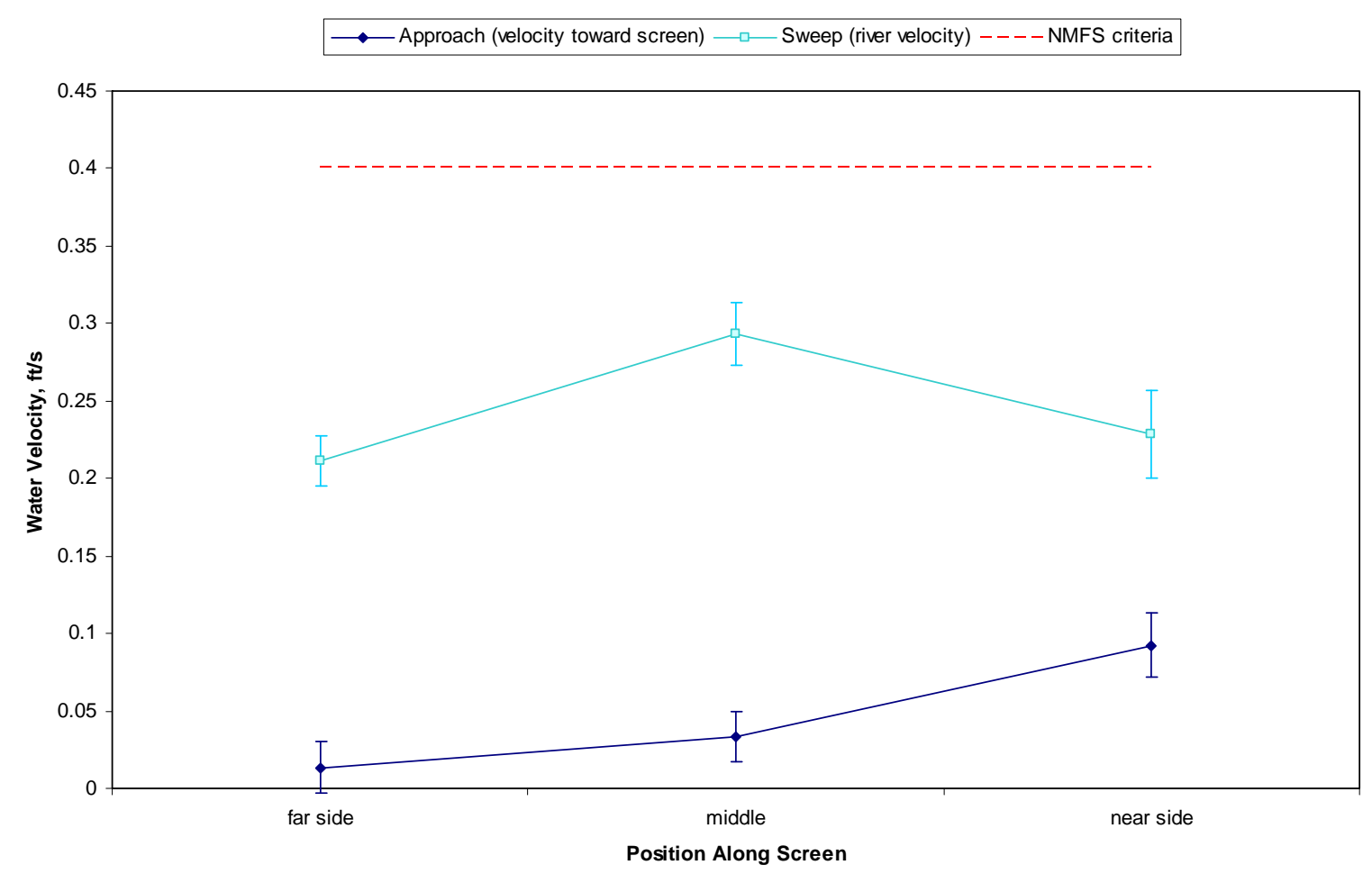

Figure 2. Dallas Thompson Riverscreen Water Velocities, June 2007. Error bars represent turbulence. Near side is closest to shore and to the pump.

\section{References}

Chamness, MA, CS Abernethy, and C. Tunnicliffe. 2007. Walla Walla River Basin Fish Screens Evaluations, 2006 Annual Report. DOE/BP-00000652-36, prepared by Pacific Northwest National Laboratory for the Division of Fish and Wildlife, Bonneville Power Administration, Portland, Oregon.

National Marine Fisheries Service (NMFS). 1995. Juvenile Fish Screen Criteria. National Marine Fisheries Service Environmental \& Technical Services Division, Portland, Oregon. 